\title{
Adsorption and reaction of ethene on oxide- supported Pd, Rh, and Ir particles
}

Cite as: Journal of Vacuum Science \& Technology A 19, 1497 (2001); https://doi.org/10.1116/1.1336828

Submitted: 07 September 2000 . Accepted: 06 November 2000. Published Online: 13 July 2001

Martin Frank, Marcus Bäumer, Ralf Kühnemuth, and Hans-Joachim Freund

ARTICLES YOU MAY BE INTERESTED IN

Surface treatment and characterization of PMMA, PHEMA, and PHPMA

Journal of Vacuum Science \& Technology A 19, 1490 (2001); https://doi.org/10.1116/1.1382650

Insight into the description of van der Waals forces for benzene adsorption on transition metal (111) surfaces

The Journal of Chemical Physics 140, 084704 (2014); https://doi.org/10.1063/1.4866175

\section{AVs Quantum Science}

Co-Published by

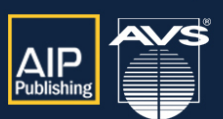

RECEIVE THE LATEST UPDATES 


\title{
Adsorption and reaction of ethene on oxide-supported Pd, Rh, and Ir particles
}

\author{
Martin Frank, Marcus Bäumer, ${ }^{\text {a) }}$ Ralf Kühnemuth, ${ }^{\text {b) }}$ and Hans-Joachim Freund \\ Fritz-Haber-Institut der Max-Planck-Gesellschaft, Faradayweg 4-6, D-14195 Berlin, Germany
}

(Received 7 September 2000; accepted 6 November 2000)

\begin{abstract}
Supported metal clusters and nanoparticles are of fundamental and technical interest, their use in heterogeneous catalysis being of particular importance. Yet on the atomic scale, there is only limited knowledge about the dependence of adsorption behavior and catalytic activity on particle size and morphology. In order to contribute to an understanding of such relationships in the case of hydrocarbon reactivity, we have studied the interaction of ethene with alumina-supported $\mathrm{Pd}, \mathrm{Rh}$, and Ir particles. Aggregates ranging in size from a few atoms up to several thousand atoms were prepared by metal vapor deposition onto a planar oxide support under ultrahigh vacuum conditions. The adsorption and dehydrogenation of ethene have been investigated by infrared and photoelectron spectroscopy. The infrared data reveal the formation of both $\pi$ and di- $\sigma$ bonded species upon adsorption at $90 \mathrm{~K}$. On Pd, this involves a net charge transfer from the adsorbate to the metal, as shown by infrared spectra of co-adsorbed carbon monoxide. Upon heating to room temperature, the ethene adlayers on $\mathrm{Rh}$ and Ir deposits dehydrogenate to ethylidyne. In the case of Pd particles, this process is accompanied by the desorption of a particle-size-dependent fraction of the ethene. (C) 2001 American Vacuum Society. [DOI: 10.1116/1.1336828]
\end{abstract}

\section{INTRODUCTION}

The hydrocarbon conversion on supported transition metal catalysts plays a key role in the chemical industry. In order to optimize such processes, it is desirable to understand the chemistry of these catalytic systems at a molecular level. Here, surface science with the large arsenal of surface analytical tools can make valuable contributions if suitable model systems are utilized. ${ }^{1,2}$ In this article, we describe a study of that kind, which deals with the adsorption and dehydrogenation of ethene on oxide-supported $\mathrm{Pd}, \mathrm{Rh}$, and $\mathrm{Ir}$ particles.

In the gas phase, ethene is a planar molecule with an $s p^{2}$ hybridization of the two carbon atoms. If the molecule is adsorbed on a metal surface, different adsorption geometries may be found [see Ref. 3 and refs. therein]. In the case of a weak interaction with the metal, the $s p^{2}$ hybridization of the carbon atoms is nearly preserved and the resulting species, called $\pi$ bonded ethene, is usually terminally bonded to a single metal atom. A stronger interaction shifts the hybridization to $s p^{3}$ and finally leads to a geometry in which the molecule is multiply coordinated to the metal. This species is referred to as di- $\sigma$ bonded ethene. An intermediate metallocyclopropane structure, denoted as $(\pi \sigma)$ bonded ethene, has been occasionally reported as well. ${ }^{3}$

Both species have been shown to play different parts in metal catalyzed hydrogenation and dehydrogenation reactions. ${ }^{3,4} \pi$ bonded ethene, for instance, is regarded as the primary intermediate in ethylene hydrogenation. Its increased occurrence on the more open single crystal surfaces, on supported metal films, and on highly dispersed catalysts points to a preferred formation at low-coordinated metal

\footnotetext{
a) Author to whom correspondence should be addressed; electronic mail: baeumer@fhi-berlin.mpg.de

${ }^{b}$ Present adress:: Max-Planck-Institut für Biophysikalische Chemie, Am Fassberg 11, D-37077 Göttingen, Germany.
}

atoms $\mathrm{s}^{3,5}$ [corroborated by theoretical calculations on the adsorption of ethene on Pt (Ref. 6)]. Di- $\sigma$ bonded ethylene, on the other hand, dehydrogenates to a $\mathrm{C}_{2} \mathrm{H}_{3}$ species, called ethylidyne ( $\left.\equiv \mathrm{C}-\mathrm{CH}_{3}\right)$, around room temperature. In hydrogenation reactions, both di- $\sigma$ bonded ethylene and ethylidyne seem to be only spectator species. ${ }^{4}$

While, for single crystals, many articles regarding ethene adsorption and reaction at liquid nitrogen temperature can be found in the literature, studies reported for supported Pd, Rh, or Ir particles so far have been carried out at substantially higher temperatures. ${ }^{3}$ This is in so far unfortunate as partial thermal dehydrogenation could not be avoided. Therefore, we have performed a detailed model study on aluminasupported $\mathrm{Pd}, \mathrm{Rh}$, and Ir particles, including the temperature range down to $90 \mathrm{~K}$. As support, a thin $\mathrm{Al}_{2} \mathrm{O}_{3}$ film, grown on $\mathrm{NiAl}(110)$, has been employed. ${ }^{7,8}$ This has the advantage that all experimental methods which rely on good electrical and thermal conductivity may be applied without restrictions. ${ }^{9}$ The particles were prepared by metal vapor deposition onto the film. As described in detail elsewhere, ${ }^{7,8}$ a large spectrum of particle sizes ranging from a few atoms to several hundred or thousand atoms is accessible in this manner. The interaction of ethene with these systems has been studied by infrared and photoelectron spectroscopy. The corresponding results will be discussed along the following lines: adsorption at $90 \mathrm{~K}(A)$, dehydrogenation upon heating to $300 \mathrm{~K}(B)$, and adsorption at $300 \mathrm{~K}(C)$.

\section{EXPERIMENT}

The results presented here have been obtained in an ultrahigh vacuum (UHV) system equipped with a Bruker IFS $66 \mathrm{v} / \mathrm{S}$ infrared spectrometer and a hemispherical analyzer (Scienta) used in conjunction with an x-ray gun. The infrared spectrometer is operated in reflection geometry (angle of incidence: $84^{\circ}$ ) and was set to a spectral resolution of about 2 
$\mathrm{cm}^{-1}$. In addition to the instruments required for the preparation of the samples, the system contains a scanning tunneling microscope (Omicron). The sample is mounted on a sample carrier allowing the transfer between the different experimental stages. In order to control the crystal temperature, a $\mathrm{NiCr} / \mathrm{Ni}$ thermocouple is spot-welded to the sample edge.

The clean $\mathrm{NiAl}(110)$ surface was prepared by several cycles of ion sputtering ( $\mathrm{Ar}^{+}$ions, $1.5 \mathrm{keV}$ ) and annealing to $1300 \mathrm{~K}$. The ordered $\mathrm{Al}_{2} \mathrm{O}_{3}$ film was obtained as previously reported in the literature. ${ }^{7,10}$ After dosage of about $5000 \mathrm{~L} \mathrm{O}_{2}$ ( $1 \mathrm{~L}=10^{-6}$ Torrs) at a sample temperature of $550 \mathrm{~K}$, the crystal was briefly annealed to $1250 \mathrm{~K}$. The quality of the oxide film was checked by scanning tunneling microscopy (STM) and on the basis of the phonon bands in the infrared spectra. With respect to the adsorption experiments, it is important to note that ethene does not adsorb on the clean film at $90 \mathrm{~K}$ or above. ${ }^{11}$

$\mathrm{Pd}, \mathrm{Rh}$, and $\mathrm{Ir}$ were evaporated from a rod (Heraeus, $>99.9 \%$ ) with a commercial electron bombardment evaporator (EMF 3T, Focus). During deposition, the crystal was biased with a retarding voltage in order to avoid the creation of point defects on the film due to metal ions accelerated towards the sample. The flux of the evaporator was calibrated by a quartz microbalance and checked by STM (via deposition of submonolayer amounts of the metals onto the clean $\mathrm{NiAl}$ crystal where a two-dimensional growth mode is observed). The evaporation rates varied between $0.1-0.45$ ML $\min ^{-1}$ (ML: monolayer). The sample temperature during deposition was $90 \mathrm{~K}$ in all cases. As discussed in Ref. 7, only disordered particles are formed under these conditions. For the adsorption, coadsorption, and dehydrogenation experiments, $\mathrm{C}_{2} \mathrm{H}_{4}$ (AGA, 99.95\%) and $\mathrm{CO}$ (AGA, 99.997\%) were employed.

\section{RESULTS AND DISCUSSION}

\section{A. Adsorption at $90 \mathrm{~K}$}

In Fig. 1, a series of infrared spectra is presented that has been recorded after saturating $\mathrm{Pd}$ particles of different sizes with ethene at $90 \mathrm{~K}$. A number of signals appear in the $\mathrm{C}-\mathrm{H}$ stretching region (left-hand side) as well as in the region of the $\mathrm{C}-\mathrm{C}$ stretching/ $\mathrm{CH}_{2}$ scissoring vibrations (right-hand side), which point to the presence of two differently coordinated species. Whereas the majority of the signals, i.e., the peaks at 1238,1513 , and $2967 \mathrm{~cm}^{-1}$, can be assigned to a $\pi$ bonded species, the bands at $2924 \mathrm{~cm}^{-1}$ and, possibly, at $1115 \mathrm{~cm}^{-1}$ indicate the presence of $\mathrm{di}-\sigma$ bonded ethene as well. ${ }^{3,12}$ Signals due to ethylidyne, expected around 1090, 1330 , and $2870 \mathrm{~cm}^{-1,3,12-14}$ are not observed. Accordingly, dehydrogenation can indeed be avoided at this temperature.

When examining the changes in the spectra as a function of particle size, the data suggest a decreasing fraction of di- $\sigma$ bonded species as the particle size decreases. As mentioned in the Introduction of this article, this is in line with the general finding that $\pi$ bonded species are preferentially formed on open surfaces and finely divided metal catalysts. ${ }^{3,5}$ Another aspect, which is worth noting, concerns

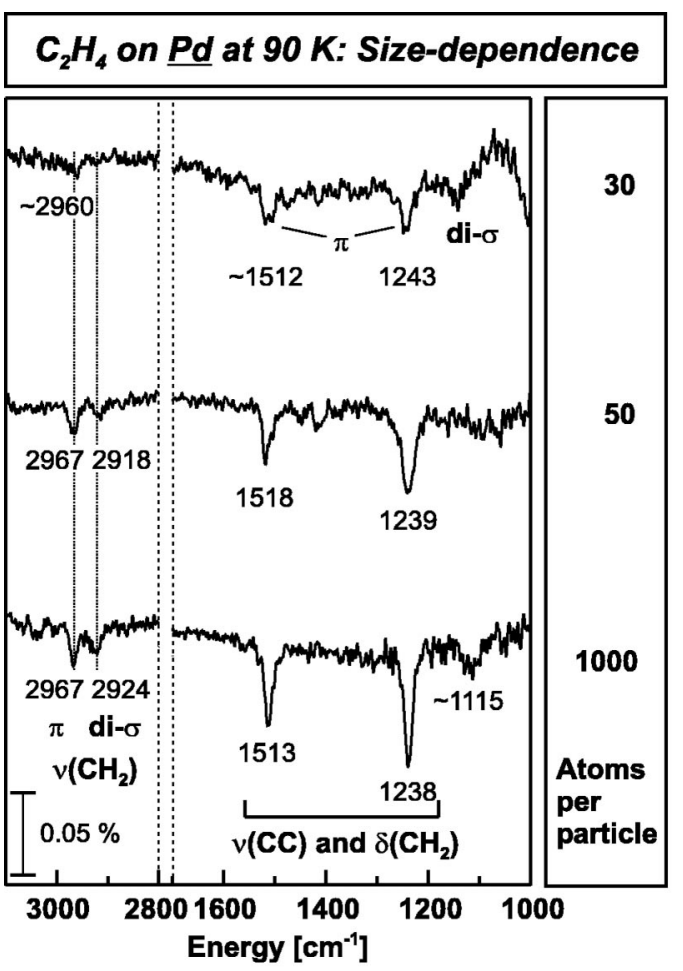

FIG. 1. Infrared spectra (taken in reflection geometry) of ethene-saturated $\mathrm{Pd}$ particles of various sizes (ethene exposure and data acquisition at $90 \mathrm{~K}$ ).

the frequencies of the signals. No major frequency shift is detectable in the series implying a particle-size-independent interaction of the molecule with the metal. This is a first indication of a constant reactivity towards the adsorbed molecules as indeed found for the hydrogenation reaction (Refs. 3,4 , and 15).

The infrared spectra of ethene-saturated Ir and Rh deposits, presented in Fig. 2, essentially resemble the data obtained for $\mathrm{Pd}$. In contrast to $\mathrm{Pd}$, however, the signatures in the $\mathrm{C}-\mathrm{H}$ stretching region are less specific so that distinct conclusions regarding the abundance of di- $\sigma$ bonded molecules cannot be drawn here. (The relatively low intensity below $2950 \mathrm{~cm}^{-1}$ may be taken as an indication that the fraction of di- $\sigma$ bonded species on Ir and Rh is not high.) Regarding the $\pi$ bonded species, a comparison of the signal frequencies in the $\mathrm{C}-\mathrm{C}$ stretching $/ \mathrm{CH}_{2}$ scissoring region reveals a distinct redshift in the series: $\mathrm{Pd} \rightarrow \mathrm{Rh} \rightarrow \mathrm{Ir}$.

In order to quantify the latter observation, we have determined the $\pi \sigma$ parameter as proposed by Stuve and Madix: ${ }^{16}$ $\pi \sigma=[(1623$-band I)/1623) $+($ 1342-band II $) / 1342] / 0.366$.

["Band I" refers to the higher $\left(1623 \mathrm{~cm}^{-1}\right)$ and "band II" to the lower frequency $\left(1342 \mathrm{~cm}^{-1}\right)$ of the $\mathrm{C}-\mathrm{C}$ stretch$\mathrm{CH}_{2}$ scissor coupled pair.] The parameter is a semiquantitative measure of the rehybridization of the adsorbed ethene molecule: the higher its value (ranging from 0 to 1 ), the larger the extent of $s p^{3}$ hybridization.

Making use of Eq. (1), we obtain values of $\sim 0.40$ for $\mathrm{Pd}$, $\sim 0.48$ for $\mathrm{Rh}$, and $0.55-0.6$ for $\mathrm{Ir}$, in very good agreement with results obtained for $\pi$ bonded ethylene on $\mathrm{M} / \mathrm{Al}_{2} \mathrm{O}_{3}$ 


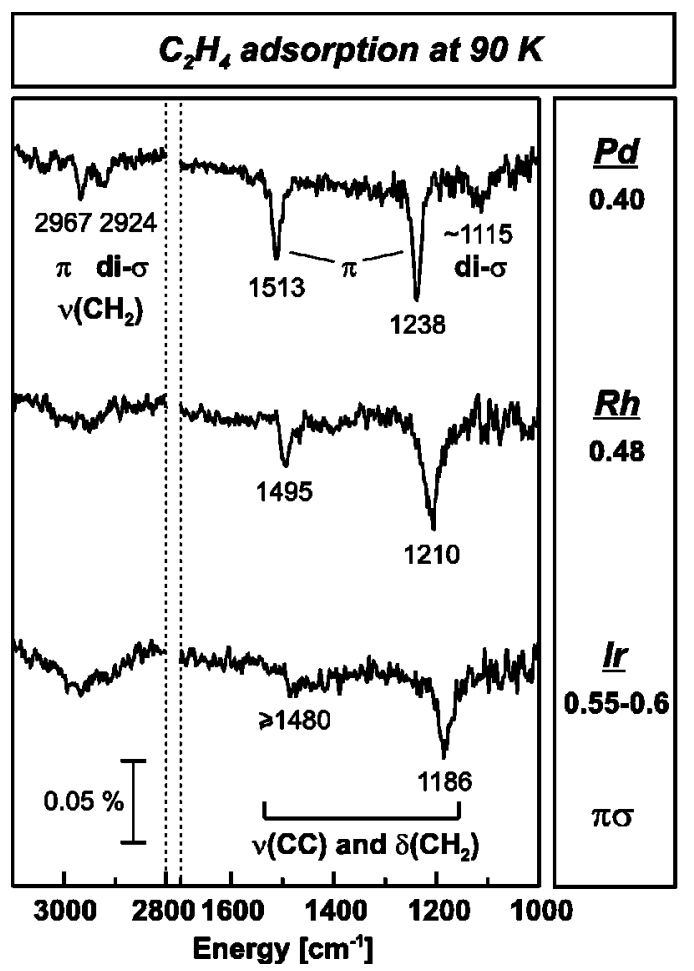

FIG. 2. Infrared spectra of Pd, Rh, and Ir particles [average particle size: 1000 atoms (Pd), 200 atoms (Rh), 350 atoms (Ir)] saturated with ethene at $90 \mathrm{~K}$ (data acquisition at $90 \mathrm{~K}$ ).

catalysts. ${ }^{12,17}$ A simple explanation for this trend, which has been proposed in the literature, ${ }^{12}$ takes the different positions of the Fermi levels into account. Since the Fermi level moves upward from Pd across Rh to Ir, the ability of the metal to donate electrons into the ethene $\pi^{*}$ orbital should increase in the series $\mathrm{Pd} \rightarrow \mathrm{Rh} \rightarrow \mathrm{Ir}$, involving a stronger rehybridization within the molecule.

However, the total charge transfer between an ethene molecule and a transition metal is given by the difference between the extent of electron donation from the ethene $\pi$ orbital to the metal on the one hand and the population of the ethene $\pi^{*}$ orbital by metal electrons on the other hand. For $\pi$ bonded ethene on $\operatorname{Pd}(111)$, the direction of the net charge flux is from the adsorbate to the metal. ${ }^{18}$ Thus, the $\pi$-donor interaction exceeds the $\pi^{*}$ back donation in this system. By contrast, theoretical results on $\mathrm{PdC}_{2} \mathrm{H}_{4}$ (Ref. 19) and $\mathrm{Pd}_{2}\left(\mathrm{C}_{2} \mathrm{H}_{4}\right)$ (Ref. 20) predict an overall charge flux from the metal to the adsorbate for both $\pi$ and di- $\sigma$ bonded ethene.

Information on charge transfer processes between adsorbates and metals may be gained utilizing $\mathrm{CO}$ as a probe molecule. To this end, one can make use of the fact that the $\mathrm{C}-\mathrm{O}$ stretching frequency is often a very sensitive indicator of the chemical environment. If direct chemical interactions between $\mathrm{CO}$ and the co-adsorbate can be ruled out, two effects have to be considered: (a) static dipole interactions through the vacuum (Stark effect) and (b) a charge transfer interaction through the surface leading to changes in the degree of metal-CO $2 \pi^{*}$ back donation and thus in the strength of the internal $\mathrm{C}-\mathrm{O}$ bond. ${ }^{21}$

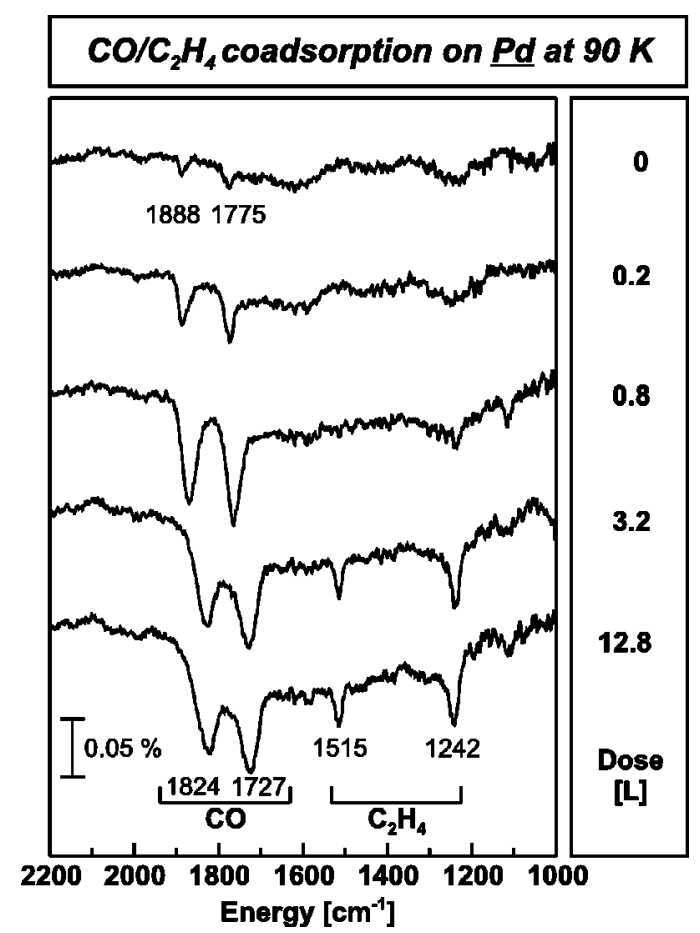

FIG. 3. Infrared spectra of Pd particles (average particle size: 800 atoms) exposed to increasing doses of a mixture of $75 \%$ ethene and $25 \% \mathrm{CO}$ at $90 \mathrm{~K}$.

In the present case, we have made use of ethene-CO co-adsorption experiments to get information on the direction of the net charge flux between ethene and the particles. Figure 3 shows a series of infrared spectra taken from a $\mathrm{Pd}$ deposit dosed with increasing amounts of an ethene-CO mixture consisting primarily of ethene $\left(75 \% \quad \mathrm{C}_{2} \mathrm{H}_{4}+25 \%\right.$ $\mathrm{CO})$. Signals due to $\pi$ bonded ethene are observed at 1242 and $1515 \mathrm{~cm}^{-1}$. These frequencies are virtually identical to those of a pure ethene adlayer (Fig. 1), proving that direct chemical interactions between the molecules are not an issue here.

At low gas exposures, the spectrum in the $\mathrm{C}-\mathrm{O}$ stretching region corresponds to that of a pure $\mathrm{CO}$ adsorbate: ${ }^{8}$ two bands are detected, a signal at $1888 \mathrm{~cm}^{-1}$, originating from bridge bonded molecules, and a signal at $1775 \mathrm{~cm}^{-1}$ due to $\mathrm{CO}$ in threefold hollow sites. ${ }^{8}$ However, upon further gas dosage, these bands shift to lower frequencies by 50 to 60 $\mathrm{cm}^{-1}$ which is at clear variance with the behavior of pure CO adlayers. For these, dipole-dipole coupling leads to a blueshift of the $\mathrm{C}-\mathrm{O}$ stretching signals (at higher coverages, the adsorption sites change as well). ${ }^{8}$ As the origin for the observed redshift, vibrational coupling between $\mathrm{CO}$ and ethene molecules can be safely excluded, since no vibrational modes of the ethene are close in frequency to the $\mathrm{C}-\mathrm{O}$ stretching bands. Hence, the redshift must be either due to a rising degree of back donation into the $\mathrm{CO} 2 \pi^{*}$ orbital or due to an interaction of the $\mathrm{CO}$ with the dipole moment associated with the $\mathrm{Pd}-\mathrm{C}_{2} \mathrm{H}_{4}$ adsorbate complex. In both cases, a charge transfer from the adsorbed ethene to $\mathrm{Pd}$ would be required to explain the direction of the frequency shift. ${ }^{21}$ Consequently, we may conclude that the behavior of 


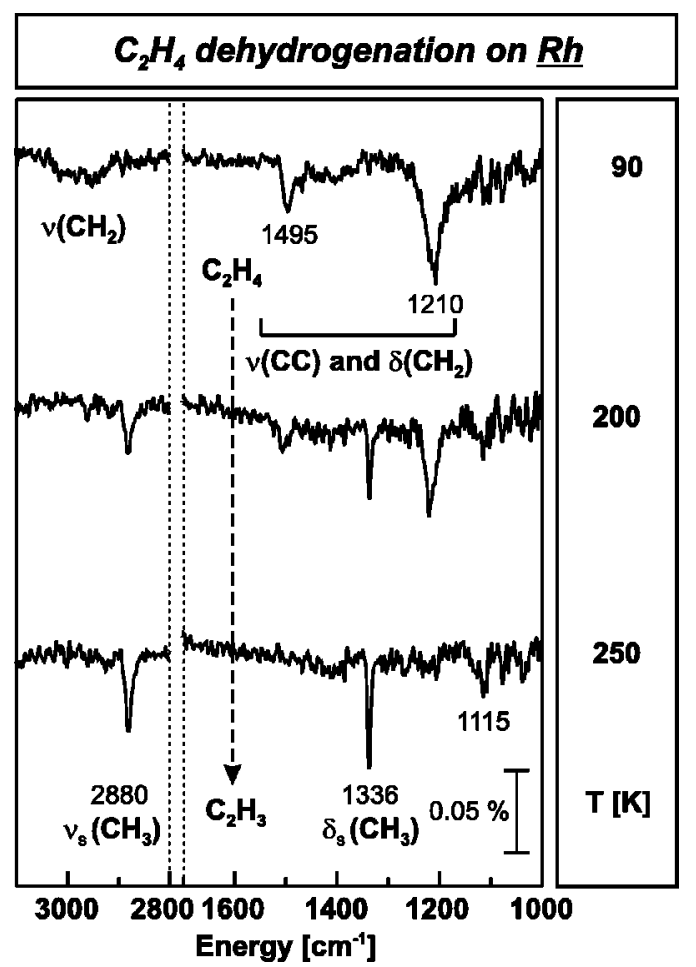

FIG. 4. Infrared spectra of Rh particles (average particle size: 200 atoms) taken after saturation with ethene at $90 \mathrm{~K}$ and annealing to the indicated temperatures (data acquisition at $90 \mathrm{~K}$ ).

ethene on the particles is analogous to its behavior on the $\operatorname{Pd}(111)$ single crystal surface. ${ }^{18}$

\section{B. Heating to $300 \mathrm{~K}$ : Dehydrogenation}

As shown for Rh in Fig. 4, warming of a pure ethene adlayer to $250 \mathrm{~K}$ results in the gradual disappearance of the infrared bands of ethene. Concomitantly, new features appear at $1336\left(\mathrm{CH}_{3}\right.$ deformation mode), $2880(\mathrm{C}-\mathrm{H}$ stretch $)$ and, possibly, $1115 \mathrm{~cm}^{-1}$, indicating dehydrogenation to ethylidyne. ${ }^{3,13,22}$

For a quantitative analysis of the dehydrogenation process, two sources of information have been used: the intensities of the ethylidyne related infrared bands and x-ray photoelectron spectroscopy (XPS) intensities. Since no major frequency shifts of the infrared bands are observed as they grow during the thermal treatment, dipole-dipole coupling seems to be negligible. Therefore, the intensities ought to be proportional to the abundance of this species. While in this way information on the ethylidyne coverage is available, XPS has been applied to determine the total carbon content on the surface. Both kind of data, the integral infrared intensity (here, the intense signal of the $\mathrm{CH}_{3}$ deformation mode was employed) as well as the integral $\mathrm{C} 1 s$ intensity, are plotted in Fig. 5 for all three metals as a function of temperature.

According to the infrared data, the ethylidyne concentration passes through a maximum at $250 \mathrm{~K}$ for $\mathrm{Ir}$ and $\mathrm{Rh}$ and at somewhat higher temperatures for Pd $(250-300 \mathrm{~K})$. These are also the temperatures at which all signals originating from adsorbed ethene have completely disappeared in the
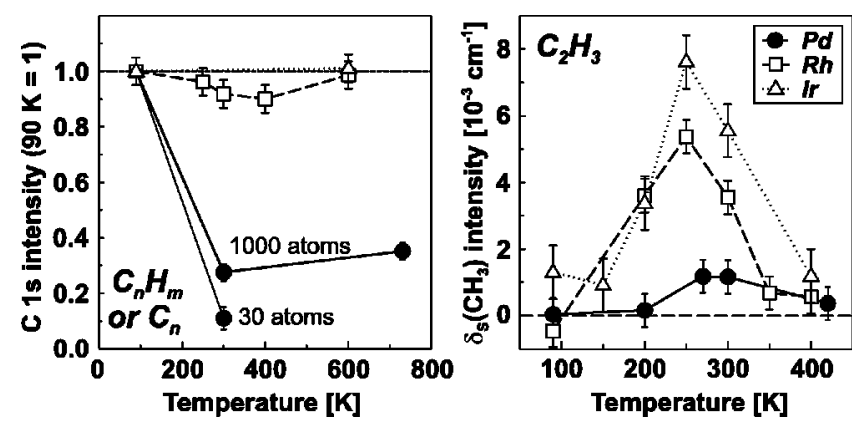

FIG. 5. Photoelectron and infrared intensities of Pd, Rh, and Ir deposits saturated with ethene at $90 \mathrm{~K}$ and annealed to higher temperatures (data acquisition at $90 \mathrm{~K}$ ): integral intensity of the $\mathrm{C} 1 \mathrm{~s}$ photoemission signal (left-hand side) and integral infrared intensity of the $\mathrm{CH}_{3}$ deformation mode of ethylidyne (right-hand side) plotted as a function of the annealing temperature. (The slight increase of the $\mathrm{C} 1 \mathrm{~s}$ intensity above $300 \mathrm{~K}$ is probably not significant.)

infrared spectra. [Similar values have been reported for $\mathrm{Rh}$ (111) (Ref. 23), whereas the temperatures for complete dehydrogenation on $\operatorname{Ir}(110)$ and $\operatorname{Ir}(111)$ are lower, i.e., 170$180 \mathrm{~K}^{24-26}$ ]

Comparing the XPS results for the three metals, interesting differences can be noticed in the temperature regime below $300 \mathrm{~K}$. While, for Rh and Ir, the carbon content essentially remains the same, a drastic loss occurs for Pd revealing that a significant fraction of ethene desorbs upon annealing to $300 \mathrm{~K}$ [in line with the behavior on $\operatorname{Pd}(111)] .{ }^{18}$ The amount of ethene desorbed depends on the particle size. For small aggregates of about 30 atoms, $90 \%$ desorb intact, i.e., $10 \%$ dehydrogenate. On larger aggregates of about 1000 atoms, $30 \%$ of the initially adsorbed ethene is subject to dehydrogenation.

Above $300 \mathrm{~K}$, no further carbon loss is detected in all three cases. Consequently, the decline of the ethylidyne concentration, deduced from the IR intensities, is not due to desorption, but due to further dehydrogenation and decomposition processes. The same behavior has been observed on supported catalysts and single crystal surfaces. ${ }^{3}$

Summing up, $\mathrm{Rh}$ and Ir show a distinctly higher dehydrogenation activity than Pd. This is consistent with the stronger interaction between the former metals and ethene discussed in Sec. III A. The particle-size-dependent dehydrogenation activity of Pd may be explained when taking the proposed role of di- $\sigma$ bonded ethene as a dehydrogenation precursor into account. Since the fraction of di- $\sigma$ bonded ethene seems to increase with increasing particle size, an enhanced activity is expected for larger aggregates in accordance with our findings. ${ }^{27}$

\section{Adsorption at $300 \mathrm{~K}$}

When the metal deposits are exposed to ethene at $300 \mathrm{~K}$, no indication of molecularly adsorbed ethene can be detected in the infrared spectra (see Fig. 6). Rather, the sharp signals of the $\mathrm{CH}_{3}$ deformation and stretching vibrations at 1328/ $2870 \mathrm{~cm}^{-1}(\mathrm{Pd}), 1336 / 2880 \mathrm{~cm}^{-1}(\mathrm{Rh})$, and $1346 / 2887 \mathrm{~cm}^{-1}$ (Ir), as well as the $\mathrm{C}-\mathrm{C}$ stretching feature at $1086 \mathrm{~cm}^{-1}$ in the Pd spectrum point to the presence of the dehydrogenation product ethylidyne. ${ }^{3,12,13}$ In the case of Ir, additional bands 


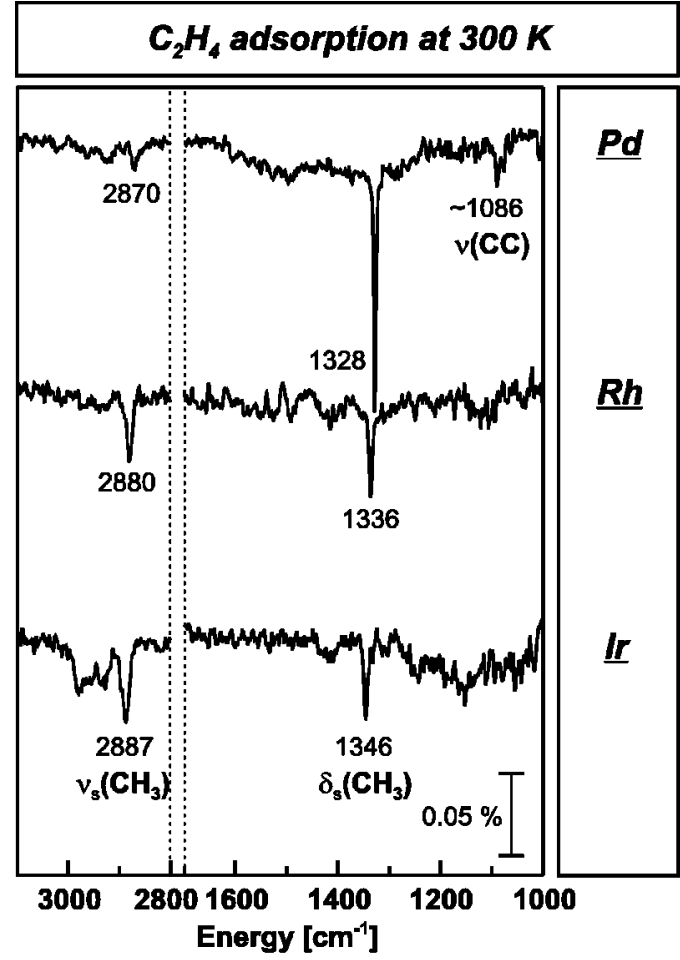

FIG. 6. Infrared spectra of Pd, Rh, and Ir particles [average particle size: 600 atoms (Pd), 200 atoms (Rh), 350 atoms (Ir)] taken after saturation with ethene at $300 \mathrm{~K}$ (data acquisition at $90 \mathrm{~K}$ ).

appear in the $\mathrm{CH}$ stretching regions between 2930 to 2980 $\mathrm{cm}^{-1}$. On single crystal surfaces and Ir particles, such signals have been assigned to ethylidyne as well. ${ }^{12,24-26}$ At this point, however, a simultaneous presence of other dehydrogenated species can not be excluded.

Whereas the findings of complete dehydrogenation upon adsorption at $300 \mathrm{~K}$ are in agreement with studies on single crystal surfaces, they differ from results obtained for technical catalysts. ${ }^{12}$ Even in the case of Ir, the most reactive metal in the series, intact ethene coexisting with ethylidyne was observed. In the literature, it has been proposed that an incomplete reduction of the catalysts might be responsible for this fact. ${ }^{28}$ At any rate, according to the present data, the stabilization of molecular ethene at room temperature is not an inherent property of the particles.

\section{CONCLUSIONS}

Adsorption of ethene on alumina-supported Pd, Rh, and Ir particles at $90 \mathrm{~K}$ results in the formation of $\pi$ and di- $\sigma$ bonded species. In the case of Pd, the infrared data suggest that the fraction of di- $\sigma$ bonded molecules increases with increasing particle size. The interaction of the $\pi$ bonded species with the metal deposits increases in the series: $\mathrm{Pd}<\mathrm{Rh}<$ Ir. Utilizing $\mathrm{CO}$ as a probe molecule, a net charge transfer from the ethene adlayer to the Pd particles has been detected.

Upon heating the adsorbed layer, dehydrogenation via ethylidyne sets in. The concentration of this intermediate passes a maximum around room temperature for all three metals. Annealing to higher temperatures involves further dehydrogenation and decomposition of the species. While dehydrogenation of the complete adlayer is observed for Ir and $\mathrm{Rh}$, the process is accompanied with an appreciable extent of ethene desorption in the case of Pd. The fraction desorbing from the deposits is particle-size-dependent and highest on small aggregates.

Adsorption of ethene on the deposits at $300 \mathrm{~K}$ is connected with the immediate dehydrogenation of the molecule. Only ethylidyne can be clearly detected under these conditions.

\section{ACKNOWLEDGMENTS}

Financial support of the following agencies is gratefully acknowledged: Deutsche Forschungsgemeinschaft, Bundesministerium für Bildung und Forschung and Fonds der chemischen Industrie. Synetix, a member of the ICI group, has supported this work through their Strategic Research Fund. One of the authors (M. F.) thanks the Studienstiftung des deutschen Volkes for a fellowship.

${ }^{1}$ C. R. Henry, Surf. Sci. Rep. 31, 231 (1998).

${ }^{2}$ H.-J. Freund, M. Bäumer, and H. Kuhlenbeck, Adv. Catal. 45, 333 (2000).

${ }^{3}$ N. Sheppard and C. de la Cruz, Adv. Catal. 41, 1 (1996).

${ }^{4}$ P. S. Cremer and G. A. Somorjai, J. Chem. Soc., Faraday Trans. 91, 3671 (1995).

${ }^{5}$ P. A. Dilara, W. T. Petrie, and J. M. Vohs, Appl. Surf. Sci. 115, 243 (1997).

${ }^{6}$ J.-F. Paul and P. Sautet, J. Phys. Chem. 98, 10906 (1994).

${ }^{7}$ M. Bäumer and H.-J. Freund, Prog. Surf. Sci. 61, 127 (1999).

${ }^{8}$ M. Frank and M. Bäumer, Phys. Chem. Chem. Phys. 2, 3723 (2000).

${ }^{9}$ D. W. Goodman, Surf. Rev. Lett. 2, 1261 (1995).

${ }^{10}$ R. M. Jaeger, H. Kuhlenbeck, H.-J. Freund, M. Wuttig, W. Hoffmann, R. Franchy, and H. Ibach, Surf. Sci. 259, 235 (1991).

${ }^{11}$ M. Frank, Ph.D. thesis, Humboldt-Universität zu Berlin, 2000.

${ }^{12}$ S. B. Mohsin, M. Trenary, and H. J. Robota, J. Phys. Chem. 95, 6657 (1991).

${ }^{13}$ T. P. Beebe, Jr. and J. T. Yates, Jr., J. Phys. Chem. 91, 254 (1987).

${ }^{14}$ M. Kaltchev, A. W. Thompson, and W. T. Tysoe, Surf. Sci. 391, 145 (1997).

${ }^{15}$ S. K. Shaikhutdinov, M. Heemeier, M. Bäumer, T. Lear, D. Lennon, R. J. Oldman, S. D. Jackson, and H.-J. Freund, J. Catal. (in press).

${ }^{16}$ E. M. Stuve, R. J. Madix, and C. R. Brundle, Surf. Sci. 152/153, 532 (1985).

${ }^{17}$ Y. Soma, J. Catal. 59, 239 (1979).

${ }^{18}$ L. P. Wang, W. T. Tysoe, R. M. Ormerod, R. M. Lambert, H. Hoffmann, and F. Zaera, J. Phys. Chem. 94, 4236 (1990).

${ }^{19}$ M. R. A. Blomberg, P. E. M. Siegbahn, and M. Svensson, J. Phys. Chem. 96, 9794 (1992).

${ }^{20}$ A. Fahmi and R. A. van Santen, J. Phys. Chem. 100, 5676 (1996).

${ }^{21}$ C. M. Mate, C.-T. Kao, and G. A. Somorjai, Surf. Sci. 206, 145 (1988).

${ }^{22}$ B. E. Koel, B. E. Bent, and G. A. Somorjai, Surf. Sci. 146, 211 (1984).

${ }^{23}$ J. N. Andersen, A. Beutler, S. L. Sorensen, R. Nyholm, B. Setlik, and D. Heskett, Chem. Phys. Lett. 269, 371 (1997).

${ }^{24}$ Ts. S. Marinova and K. L. Kostov, Surf. Sci. 181, 573 (1987).

${ }^{25}$ Ts. S. Marinova and D. V. Chakarov, Surf. Sci. 192, 275 (1987).

${ }^{26}$ D. V. Chakarov and Ts. S. Marinova, Surf. Sci. 227, 297 (1990).

${ }^{27}$ In this context, the presence of $\pi$ bonded species on Rh and Ir may seem to be in conflict with the very high dehydrogenation activity of these metals. However, the conversion of $\pi$ bonded ethene to ethylidyne might proceed via a di- $\sigma$ bonded intermediate not detected in our study; see Y.-T. Wong and R. Hoffmann, J. Chem. Soc., Faraday Trans. 86, 4083 (1990).

${ }^{28}$ D. A. Hensley and L. L. Kesmodel, J. Phys. Chem. 95, 1368 (1991). 